\title{
Growth and applications of superconducting and nonsuperconducting oxide epitaxial films
}

\author{
M S HEGDE \\ Solid State and Structural Chemistry Unit, Indian Institute of Science, Bangalore 560012 , \\ India

\begin{abstract}
Growth and characterization of high-temperature-superconducting $\mathrm{YBa}_{2} \mathrm{Cu}_{3} \mathrm{O}_{7}$ and several metallic-oxide thin films by pulsed laser deposition is described here. An overview of substrates employed for epitaxial growth of perovskite-related oxides is presented. Ag-doped $\mathrm{YBa}_{2} \mathrm{Cu}_{3} \mathrm{O}_{7}$ films grown on bare sapphire are shown to give $T_{\mathrm{c}}=90 \mathrm{~K}$, critical current $>10^{6} \mathrm{~A} / \mathrm{cm}^{2}$ at $77 \mathrm{~K}$ and surface resistance $=450 \mu \Omega$. Application of epitaxial metallic $\mathrm{LaNiO}_{3}$ thin films as an electrode for ferroelectric oxide and as a normal metal layer barrier in the superconductor-normal metal-superconductor (SNS) Josephson junction is presented. Observation of giant magnetoresistance (GMR) in the metallic $\mathrm{La}_{0 \cdot 6} \mathrm{~Pb}_{0.4} \mathrm{MnO}_{3}$ thin films up to $50 \%$ is highlighted.
\end{abstract}

Keywords. Epitaxial thin films; metallic oxides; high- $T_{\mathrm{c}}$ films; SNS junction; $\mathrm{LaNiO}_{3}$; $\mathrm{La}_{1-x} \mathrm{~Pb}_{x} \mathrm{MnO}_{3}$ : ferroelectric oxides; ferromagnetic oxides.

\section{Introduction}

Since the discovery of superconductivity at high temperature in $\mathrm{La}_{2-x} \mathrm{Ba}_{x} \mathrm{CuO}_{4}$ (Bednorz and Muller 1986) and subsequently in $\mathrm{YBa}_{2} \mathrm{Cu}_{3} \mathrm{O}_{7-x}\left(T_{\mathrm{c}}=90 \mathrm{~K}\right)$ (Wu et al 1987), extensive efforts have been made to fabricate thin films of these materials because of the high possibility of their use in electronic devices. Even though a large number of Bi- and Tl-based oxides are known to give superconducting transition temperature $T_{\mathrm{c}}>90 \mathrm{~K}$, the majority of efforts in the thin-film area still continue to be on the growth of $\mathrm{YBa}_{2} \mathrm{Cu}_{3} \mathrm{O}_{7-x}$ (YBCO) films because of the relative ease with which YBCO films can be fabricated in situ with correct composition. Further, thin films give high critical current density $\left(J_{\mathrm{c}}\right)$ routinely at $77 \mathrm{~K}$. Chaudhari et al (1987) were the first to show that $J_{\mathrm{c}}$ as high as $10^{6} \mathrm{~A} / \mathrm{cm}^{2}$ can be achieved in epitaxially grown YBCO films on $\langle 100\rangle \mathrm{SrTiO}_{3}$ (STO) substrates. Pulsed laser deposition (PLD) is the most successful technique among the commonly used methods to fabricate good quality high- $T_{c}$ thin films. PLD has also been extended to grow a variety of epitaxial nonsuperconducting oxide thin films for superconductor-insulator-superconductor (SIS) and superconductor-normal metal (metallic oxide)-superconductor (SNS) trilayer heterojunctions. These types of multilayer structures are required to realize Josephson junctions for superconducting quantum interference device (SQUID) fabrication.

The fabrication of trilayer junctions using YBCO films as superconductor and $\mathrm{PrBa}_{2} \mathrm{Cu}_{3} \mathrm{O}_{7}$ (PBCO) as insulating barrier was reported for the first time by Rogers et al (1989). The trilayer junction fabricated by them did show Josephson-junction $(\mathrm{JJ})$ behaviour, but the current $(I)$-voltage $(V)$ characteristic of the junction was unlike the $I-V$ characteristic of SIS junction fabricated out of the classical superconductors and insulating barriers such as $\mathrm{Nb}-\mathrm{Al}_{2} \mathrm{O}_{3}-\mathrm{Nb}$. Subsequent attempts to make SIS 
junctions using other insulating layer like $\mathrm{NdGaO}_{3}$ or $\mathrm{NdAlO}_{3}$ also showed only the SNS type of $I-V$ characteristics. Therefore attempts were made to fabricate SNS Josephson junctions with perovskite-related metallic oxides as the N-metal barrier layer (Char et al 1993). Thus fabrication of epitaxial thin films of perovskite-related metallic oxides itself became an important aspect of research in conjunction with high- $T_{\mathrm{c}}$ oxides. Further, perovskite-related metallic oxides could also be used as electrodes for ferroelectric oxide capacitors. Another advantage of epitaxial oxide thin films was that they are essentially single-crystal-like materials and unusual properties such as giant magnetoresistance (GMR) in lanthanum manganates could be realized (Searle and Wang 1970).

Realizing the importance of this area of research, we have set up a PLD system (Dijkkamp et al 1987; Inam et al 1988; Srinivasu et al 1991) in our laboratory to fabricate high-temperature-superconducting and related oxide thin films. In this article, we will present an overview of the substrates employed for epitaxial growth of perovskite-related oxide thin films and some of the recent results that we have obtained on (a) Ag-doped $\mathrm{YBa}_{2} \mathrm{Cu}_{3} \mathrm{O}_{7-x}(\mathrm{Ag}-\mathrm{YBCO}$ ) thin films, (b) fabrication of epitaxial metallic $\mathrm{LaNiO}_{3}$ thin films, (c) fabrication and properties of $\mathrm{YBCO} / \mathrm{LaNiO}_{3} /$ YBCO trilayer junctions, (d) $\mathrm{LaNiO}_{3}$ thin-film electrodes for $\mathrm{Bi}_{2} \mathrm{VO}_{5.5}$ ferroelectric oxide, and (e) giant magnetoresistance in epitaxial $\mathrm{La}_{0 \cdot 6} \mathrm{~Pb}_{0.4} \mathrm{MnO}_{3}$ thin films.

\section{Experimental}

The PLD experiments for the growth of $\mathrm{YBa}_{2} \mathrm{Cu}_{3} \mathrm{O}_{7}, \mathrm{LaNiO}_{3}$ and other related oxide films were carried out using $\operatorname{KrF}(\lambda=248 \mathrm{~nm})$ excimer laser with a $300 \mathrm{~mm}$ focal length quartz lens for focusing the laser beam. The excimer pulse had maximum energy of $1000 \mathrm{~mJ}$ with a pulse width of $25 \mathrm{~ns}$ and $1-10 \mathrm{~Hz}$ of variable repetition rate. The laser fluence was varied from 1.5 to $2.5 \mathrm{~J} / \mathrm{cm}^{2}$ by varying the laser pulse energy and quartz attenuators. A schematic diagram of the experimental set-up is given in figure 1. For thin-film deposition, the substrates were held on the surface of the heater face plate by Ag paste and the temperature on the surface of the heater was measured using a chromel-alumel thermocouple fixed onto it by $\mathrm{Ag}$ paste. The temperature difference between the heater face plate and the substrate top surface was about $30-40^{\circ} \mathrm{C}$ which was calibrated by fixing another thermocouple on the top surface of substrate. The oxygen pressure during film deposition was maintained at about 200-450 $\mathrm{m}$ torr depending on the material. The deposition temperature was optimized separately for each material, and it was about $780^{\circ} \mathrm{C}$ for $\mathrm{YBCO}$. The growth and structural properties of high-temperature-superconducting oxide and other oxide films have been reported in detail in our earlier publications (Srinivasu et al 1991; Hegde et al 1993, 1994; Satyalakshmi et al 1993; Prasad et al 1993).

The YBCO/LNO/YBCO trilayer structure was fabricated by depositing YBCO film first on the complete surface of STO and subsequently depositing LNO on the previously deposited YBCO film by masking one side of the film by silver foil. This was followed by the deposition of YBCO on the central region of LNO by masking the remaining portion with silver foil. The structural characterization of all the individual films as well as of the trilayer was carried out using X-ray diffraction (XRD), scanning electron microscopy (SEM) and energy dispersive $\mathrm{X}$-ray analysis (EDAX). The conductivity measurements were carried out by a four-probe method 


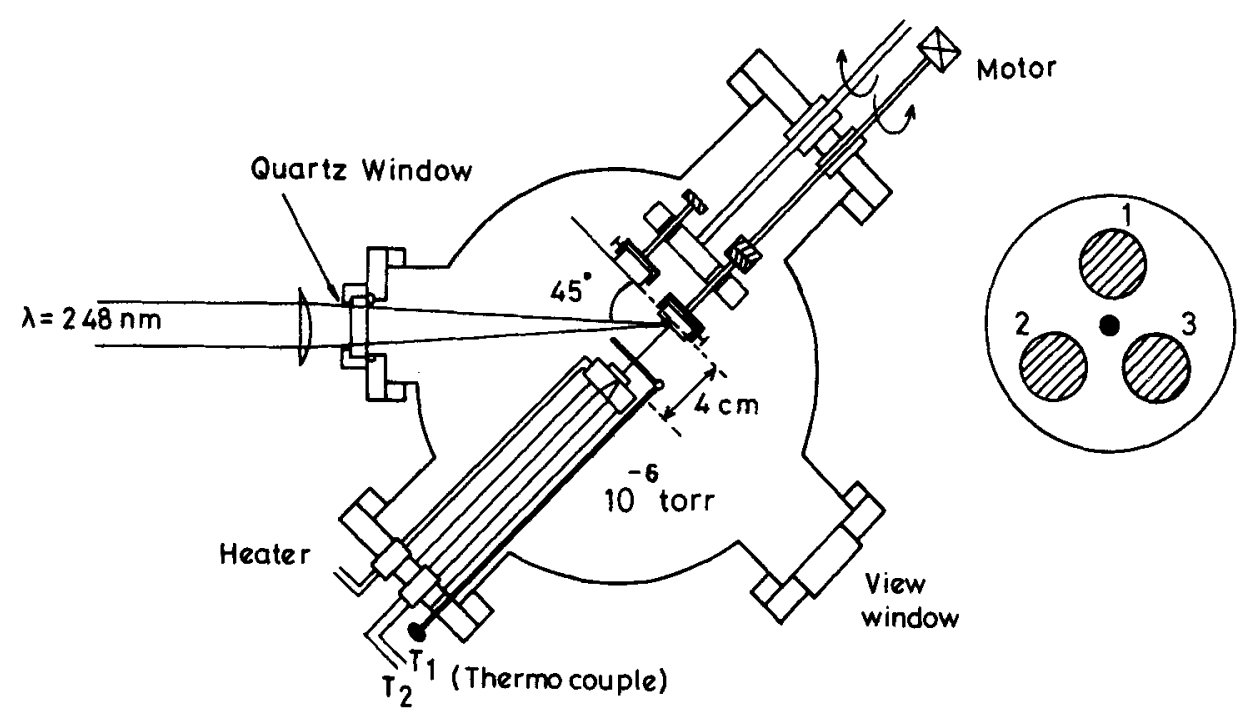

Figure 1. Triple target pulsed laser deposition system.

and the $I-V$ characteristics of the trilayer were determined using laser-patterned mirobridges.

\section{Substrates for epitaxial growth of $\mathrm{YBa}_{2} \mathrm{Cu}_{3} \mathrm{O}_{7}(\mathrm{YBCO})$ and related oxide films}

As mentioned earlier, the breakthrough to realize high $T_{\mathrm{c}}$, and high $J_{\mathrm{c}}$ came only when the YBCO epitaxial thin films were grown on $\mathrm{SrTiO}_{3}(100)$ single-crystal substrate by Chaudhari et al (1987). Ability to grow in situ YBCO films in the as-deposited condition giving $T_{\mathrm{c}} 90 \mathrm{~K}$ by introducing oxygen during the deposition was a significant step towards the use of YBCO films for high- $T_{\mathrm{c}}$ applications (Inam et al 1988). A large number of single-crystal substrates have been employed to fabricate YBCO and other oxide films. YBCO has the lattice parameters $a=3.83 \AA, b=3.89 \AA$ and $c=11.65 \AA$. General criteria for the epitaxial growth of these high- $T_{c}$ oxide films are summarized below:

(i) The substrate should have structural compatibility, i.e. possess cubic and perovskite-related structure.

(ii) The lattice parameter of the substrate should be within $5 \%$ of the lattice parameters of high- $T_{\mathrm{c}}$ oxides.

(iii) These substrates should have thermal expansion coefficients close to that of YBCO itself. Otherwise, due to thermal shock during cooling, the grown films are known to develop microcracks leading to discontinuity in the films.

(iv) The substrate should be chemically and structurally stable at the processing temperature of $\mathrm{YBCO}$, which is generally around $750-800^{\circ} \mathrm{C}$.

(v) The substrate material should be chemically compatible in terms of the nature of chemical bond.

In table 1, we summarize the structure, lattice parameters, thermal expansion coefficient and dielectric constant of a variety of substrate materials. The single crystals 
Table 1. Structure, lattice parameters and physical properties of substrates for epitaxial growth of $\mathrm{YBa}_{2} \mathrm{Cu}_{3} \mathrm{O}_{7}$ thin films.

\begin{tabular}{|c|c|c|c|c|}
\hline $\begin{array}{l}\text { Substrate } \\
\text { material }\end{array}$ & $\begin{array}{l}\text { Crystal } \\
\text { structure }\end{array}$ & $\begin{array}{l}\text { Lattice } \\
\text { parameters } \\
(\AA)\end{array}$ & $\begin{array}{c}\text { Thermal } \\
\text { expansion } \\
\text { coefficient } \\
\left(10^{-6} / \mathrm{K}\right)\end{array}$ & $\begin{array}{l}\text { Dielectric } \\
\text { constant }\end{array}$ \\
\hline $\mathrm{SrTiO}_{3}$ & $\begin{array}{l}\text { Cubic } \\
\text { (perovskite) }\end{array}$ & $a=3.905$ & $9 \cdot 4-10.8$ & 7300 \\
\hline $\mathrm{LaGaO}_{3}$ & $\begin{array}{l}\text { Orthorhombic } \\
\text { (distorted } \\
\text { perovskite) } \\
\left(\mathrm{GdFeO}_{3}\right)\end{array}$ & $\begin{aligned} a & =5.482 \\
b & =5.526 \\
c & =7.78 \\
\left({ }^{*} a_{0}\right. & =3.892)\end{aligned}$ & $10 \cdot 6$ & 25 \\
\hline $\mathrm{LaAlO}_{3}$ & $\begin{array}{l}\text { Rhombohedral } \\
\text { (distorted } \\
\text { perovskite) }\end{array}$ & $\begin{aligned} a & =5.364 \\
c & =13.11 \\
\left(a_{0}\right. & =3.788)\end{aligned}$ & 10 & 16 \\
\hline YSZ & $\begin{array}{l}\text { Cubic } \\
\text { (fluorite) }\end{array}$ & $\begin{aligned} a & =5 \cdot 16 \\
\left(a_{0}\right. & =3.65)\end{aligned}$ & $9 \cdot 2-10-3$ & 27 \\
\hline $\mathrm{MgO}$ & $\begin{array}{l}\text { Cubic } \\
(\mathrm{NaCl})\end{array}$ & $a=4 \cdot 212$ & 13.8 & 14 \\
\hline $\begin{array}{l}\mathrm{Al}_{2} \mathrm{O}_{3} \\
\text { (sapphire) }\end{array}$ & Trigonal & $\begin{aligned} a & =5.14 \\
\left(a_{0}\right. & =3.64)\end{aligned}$ & 5 & 10 \\
\hline $\mathrm{Si}$ & Diamond & $\begin{aligned} a & =5.43 \\
\left(a_{0}\right. & =3.83)\end{aligned}$ & 6.7 & 12 \\
\hline $\mathrm{KTaO}_{3}$ & $\begin{array}{l}\text { Cubic } \\
\text { (perovskite) }\end{array}$ & $a=3.989$ & - & - \\
\hline $\mathrm{BaTiO}_{3}$ & $\begin{array}{l}\text { Tetragonal } \\
\text { (perovskite) }\end{array}$ & $\begin{array}{l}a=3.99 \\
c=4.03\end{array}$ & 19 & $>2000$ \\
\hline $\mathrm{LaSrGaO}_{4}$ & $\begin{array}{l}\text { Tetragonal } \\
\left(\mathrm{K}_{2} \mathrm{NiF}_{4}\right)\end{array}$ & $\begin{array}{l}a=3.843 \\
c=12.861\end{array}$ & - & - \\
\hline $\mathrm{Y}_{3} \mathrm{Fe}_{5} \mathrm{O}_{12}$ & Garnet & $\begin{aligned} a & =12 \cdot 376 \\
\left(a_{0}\right. & =4 \cdot 125)\end{aligned}$ & - & - \\
\hline $\mathrm{YbFeO}_{3}$ & $\begin{array}{l}\text { Orthorhombic } \\
\left(\mathrm{GdFeO}_{3}\right)\end{array}$ & $\begin{aligned} a & =5.36 \\
b & =5.50 \\
c & =7.77 \\
\left(a_{0}\right. & =3.86)\end{aligned}$ & - & $4-5$ \\
\hline $\mathrm{BaFe}_{12} \mathrm{O}_{19}$ & $\begin{array}{l}\text { Barium } \\
\text { orthoferrite }\end{array}$ & $\begin{aligned} a & =5 \cdot 88 \\
c & =23 \cdot 22 \\
\left(a_{0}\right. & =4 \cdot 158)\end{aligned}$ & - & - \\
\hline $\mathrm{MgAl}_{2} \mathrm{O}_{4}$ & $\begin{array}{l}\text { Cubic } \\
\text { Spinel }\end{array}$ & $\begin{aligned} a & =8.059 \\
\left(a_{0}\right. & =4.029)\end{aligned}$ & 76 & - \\
\hline $\mathrm{YBa}_{2} \mathrm{Cu}_{3} \mathrm{O}_{7}$ & $\begin{array}{l}\text { Triple } \\
\text { Perovskite }\end{array}$ & $\begin{array}{l}a=3.83 \\
b=3.89 \\
c=11.65\end{array}$ & 12 & - \\
\hline
\end{tabular}

* $a_{0}$, Pseudocubic parameter

of these materials have been employed to grow epitaxial thin films of YBCO. Single crystals of these materials cut in the $\langle 100\rangle$ direction generally support $c$-axis growth. Thus $\langle 100\rangle$ surface of the substrate supports epitaxial growth, the $a-b$ plane of YBCO aligned parallel to $\langle 100\rangle$ of the substrate. Some of these substrates are also used for the growth of perovskite-related metallic and ferroelectric oxide thin films.

Among these materials, $\mathrm{SrTiO}_{3}$ (STO) is a widely used substrate for the growth of $\mathrm{YBCO}$ and it is known to give the highest critical current density $\left(10^{6} \mathrm{~A} / \mathrm{cm}^{2}\right.$ at 
$77 \mathrm{~K}$ ) for epitaxial YBCO films. This is due to the very small lattice mismatch between YBCO and STO. STO is a good lattice-matched substrate, but due to the large dielectric constant, the films grown on this substrate are not good for microwave applications. $\mathrm{LaAlO}_{3}$ (LAO) single crystal is a commonly used substrate because it is relatively less expensive and high- $J_{c}, 90 \mathrm{~K}$ YBCO films on $\mathrm{LAO}$ are routinely grown. $\mathrm{LaGaO}_{3}$ is the best known substrate for YBCO thin-film growth but it is not readily available and it is expensive. Both MgO and YSZ are relatively less expensive but both have about $5 \%$ lattice mismatch with reference to $\mathrm{YBCO}$ because of which growing highquality YBCO film is difficult compared to the films on $\mathrm{SrTiO}_{3}, \mathrm{Al}_{2} \mathrm{O}_{3}$ (sapphire) is the best-suited substrate for microwave applications. But due to the large lattice mismatch and $\mathrm{Al}$ diffusion into $\mathrm{YBCO}$ at high temperature making $\mathrm{YBCO}$ nonsuperconducting, it is difficult to grow high- $J_{\mathrm{c}}$, high- $T_{\mathrm{c}}$ YBCO films on sapphire. However, high-quality YBCO thin films have been successfully grown on sapphire by employing a yttriastabilized zirconia (YSZ) barrier layer on $\mathrm{Al}_{2} \mathrm{O}_{3}$. This minimizes the interaction between $\mathrm{YBCO}$ and $\mathrm{Al}_{2} \mathrm{O}_{3}$. We have grown Ag-doped $\mathrm{YBCO}$ on bare sapphire with excellent $T_{\mathrm{c}}(90 \mathrm{~K})$ and $J_{\mathrm{c}}\left(10^{6} \mathrm{~A} / \mathrm{cm}^{2}\right)$. The results are presented here in the next section.

Silicon is a unique material. There is a famous saying at IBM Laboratories: 'If one can use Si for any electronic applications, don't use any other!' But due to the large thermal mismatch and also the weaker bonding between covalent silicon lattice and the ionic oxides, growth of YBCO on bare silicon has not been successful so far. However, with $\mathrm{MgAl}_{2} \mathrm{O}_{4} / \mathrm{BaTiO}_{3}$ oxide layers as buffer layers on $\mathrm{Si}(100)$, the growth of YBCO, with $T_{\mathrm{c}}=85 \mathrm{~K}$, coated with these buffer layers has been achieved (Wu et al 1989).

$\mathrm{LaSrGaO}_{4}$ is an important substrate material for the growth of $a$-axis-oriented YBCO films. This is one of the important single-crystal substrates which supports high-quality $a$-axis growth of YBCO without any template buffer layer. It is important to note that oxides which are magnetically ordered, such as garnets and orthoferrites are also known to support the epitaxial growth of $\mathrm{YBCO}$ with $T_{\mathrm{c}}$ as high as $90 \mathrm{~K}$ (Ramesh et al 1989). Spinels such as $\mathrm{MgAl}_{2} \mathrm{O}_{4}$ are also found to be good latticematched material for the growth of YBCO, but it has been mainly used as a material for buffer layer. Search for new substrates, new barrier-layer materials and substrates for $a$-axis-oriented growth against $c$-axis-oriented growth of YBCO is still an active area of research.

\section{Results and discussion}

\subsection{Ag-doped YBCO films on sapphire}

High-quality epitaxial YBCO films with $c$-axis perpendicular to the (100) cut substrate plane can be characterized by the slope of $R$ vs $T$ curve. If $R_{300} / R_{100}$ is greater than 3, $T_{\mathrm{c}}$ of $90 \mathrm{~K}$ and $J_{\mathrm{c}}$ around $10^{6} \mathrm{~A} / \mathrm{cm}^{2}$ at $77 \mathrm{~K}$ are generally obtained.

Sapphire is the most important substrate which has extremely low loss in the microwave region. High- $T_{\mathrm{c}}$ films in the form of strips are used as transmitting lines without loss in the microwave region. However, growing high-quality, high- $J_{c}, 90 \mathrm{~K}$ YBCO films having low surface resistance is difficult on bare sapphire due to the large lattice mismatch and chemical interactions of $\mathrm{Al}$ with $\mathrm{YBCO}$. We have overcome 


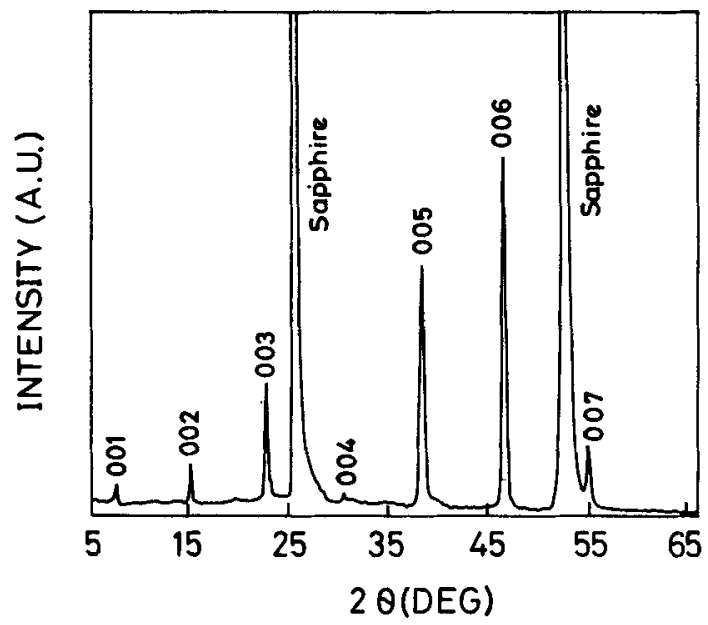

Figure 2. $\mathrm{CuK} \theta-2 \theta$ scan of $7 \%$-Ag-doped $\mathrm{YBa}_{2} \mathrm{Cu}_{3} \mathrm{O}$, films on sapphire.

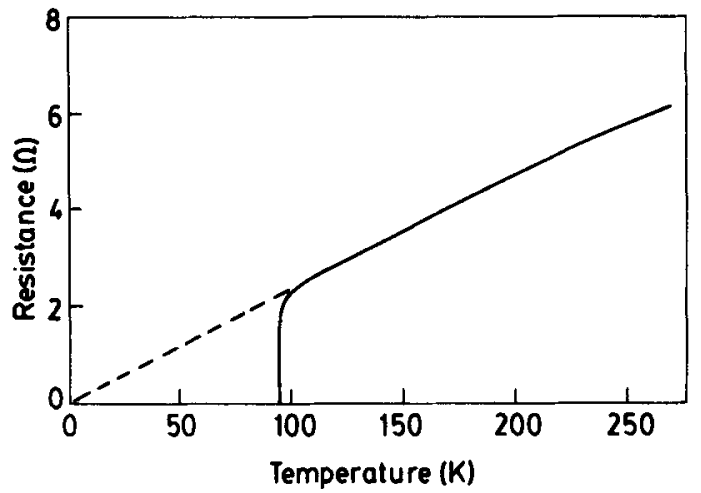

Figure 3. $R$ vs $T$ plot of the above film showing $R_{300} / R_{100} \sim 2 \cdot 9$ and $T_{\mathrm{c}}=90 \mathrm{~K}$.

this problem by growing $7 \%$-Ag-doped YBCO films on bare sapphire. Silver addition lowered the growth temperature from $780^{\circ} \mathrm{C}$ to $730^{\circ} \mathrm{C}$ in the PLD system. A typical $c$-axis-oriented Ag-doped film grown on sapphire is shown in figure 2. Figure 3 shows $R$ vs $T$ plot of Ag-doped YBCO films. The film showed $T_{\mathrm{c}}$ of $90 \mathrm{~K} . R_{300} / R_{100}$ was about 2.9. Transport critical current of these films was about $1.2 \times 10^{6} \mathrm{~A} / \mathrm{cm}^{2}$ at $77 \mathrm{~K}$. Microwave surface resistance of Ag-doped films was about $450 \mu \Omega$ at $10 \mathrm{GHz}$ at $77 \mathrm{~K}$. The $T_{\mathrm{c}}, J_{\mathrm{c}}$ values of Ag-doped YBCO films on bare sapphire reported here are the highest and surface resistance value is the lowest compared to values reported in the literature. Details of the study will be published elsewhere (Dhananjay Kumar et al, to be published). We are now using these high- $T_{\mathrm{c}}, \mathrm{Ag}$-doped YBCO films for microwave applications.

\subsection{Metallic $\mathrm{LaNiO}_{3}$ thin films}

Metallic oxide films are finding application as the normal metal barrier in the SNStype Josephson junctions, and electrodes for superconducting, insulating and ferro- 
electric oxides. Among the perovskite-related oxides, we have found that $\mathrm{LaNiO}_{3}$ (LNO) is perhaps the best material for these applications (Hegde et al 1994). Epitaxial $\mathrm{LaNiO}_{3}$ thin films have been routinely grown in this laboratory on a variety of substrates such as $\mathrm{LaAlO}_{3}, \mathrm{SrTiO}_{3}, \mathrm{MgO}, \mathrm{YSZ}, \mathrm{SiO} / \mathrm{Si}(100)$ and $\mathrm{Al}_{2} \mathrm{O}_{3}$. Typical $R$ vs $T$ plots of a few films are given in figure 4. Resistivity of these $\mathrm{LaNiO}_{3}$ films is of the order of $300-400 \mu \Omega \cdot \mathrm{cm}$. We have grown (100)-oriented $\mathrm{LaNiO}_{3}$ thin films on $\mathrm{SiO}_{2} / \mathrm{Si}(100)$ substrate for the first time even though $\mathrm{SiO}_{2}$ layer on $\mathrm{Si}(100)$ is amorphous. The reason for an oriented growth of $\mathrm{LaNiO}_{3}$ on amorphous $\mathrm{SiO}_{2}$ is not clear to us. The $\theta-2 \theta$ scan of $\mathrm{LaNiO}_{3}$ over YBCO films is shown in figure 5 . Observation of only (100) and (200) $\mathrm{LaNiO}_{3}$ lines on the epitaxial YBCO films on $\mathrm{LaAlO}_{3}(100)$ indicates epitaxial growth of LNO on YBCO. The contact conductance between metallic $\mathrm{LaNiO}_{3}$ and superconducting YBCO thin films has been measured by a modified four-probe method and the value is $1.4 \times 10^{4} \mathrm{ohm}^{-1} \mathrm{~cm}^{-2}$ at $77 \mathrm{~K}$, which is about the same as that of $\mathrm{Ag}$ and Pd with YBCO films.

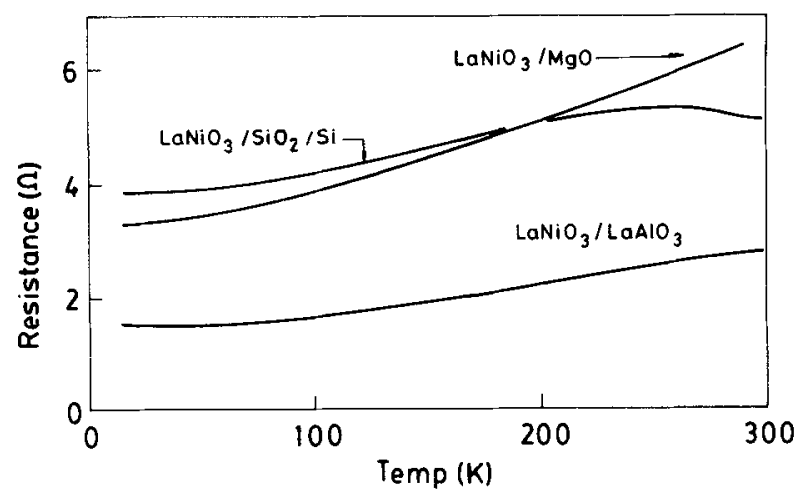

Figure 4. $R$ vs $T$ plot of $\mathrm{LaNiO}_{3}$ films on different substrates.

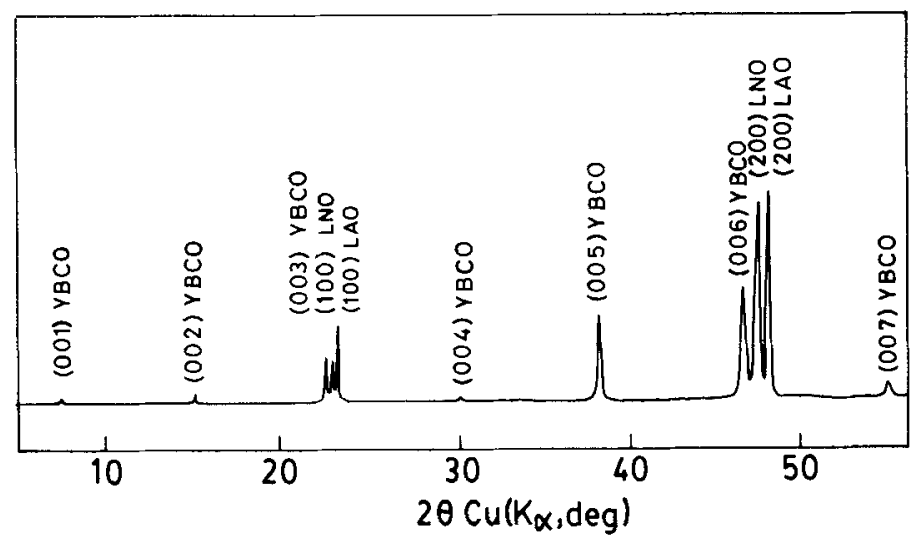

Figure 5. $\mathrm{CuK}_{\alpha} \mathrm{X}$-ray $\theta-2 \theta$ scan of $\mathrm{LaNiO}_{3}$ (LNO) films grown on $\mathrm{YBa}_{2} \mathrm{Cu}_{3} \mathrm{O}_{7}(\mathrm{YBCO})$ films deposited on $\mathrm{LaAlO}_{3}$ (LAO) substrate. 


\section{3 $\mathrm{LaNiO}_{3}$ as a normal metal barrier for SNS junction}

$\mathrm{YBCO} / \mathrm{LNO} / \mathrm{YBCO}$ trilayer structures were fabricated in the planar form with LNO barrier thickness of the order of $1000 \AA$. The $\mathrm{CuK}_{\alpha} \mathrm{X}$-ray $\theta-2 \theta$ scan of $\mathrm{YBCO} / \mathrm{LNO} /$ $\mathrm{YBCO} / \mathrm{STO}$ trilayer structure is similar to that given in figure 5. This indicates that the third (YBCO) layer grown LNO is also $c$-axis-oriented.

In order to measure the $I-V$ characteristics of the above structure, a $100 \mu \mathrm{m}$ wide and $330 \mu \mathrm{m}$ long microbridge was patterned by laser irradiation. Figure 6 shows the $I-V$ characters of the junction at $77 \mathrm{~K}$. The $T_{c}$ of the YBCO film across the LNO barrier was about $86 \mathrm{~K}$ and $J_{\mathrm{c}}$ of the junction at $77 \mathrm{~K}$ was $300 \mathrm{~A} / \mathrm{cm}^{2}$. The coherence length $\zeta_{n}$ in the normal metal (LNO) region was found to be $125 \AA$, which was calculated using the formula

$$
J_{\mathrm{c}}(d)=J_{\mathrm{co}} \exp \left(-d / \zeta_{n}\right),
$$

where $d$ is the barrier thickness.

The figure of merit of the Josephson junction $R_{n} A$ is found of the order of $10^{-9} \Omega \cdot \mathrm{cm}^{2}$, which is comparable to the values reported for SNS junctions fabricated using YBCO superconducting films with different metallic-oxide films as barrier layers (Char et al 1993).

\section{4 $\mathrm{LaNiO}_{3}$ films as electrodes for ferroelectric oxides}

The main problem of integrating ferroelectric thin films into devices is the difficulty of growing single-crystal-like films with proper electrode materials. Recent developments in oxide thin film fabrication reveal that perovskite-related metallic oxides can act as good electrodes for ferroelectric oxides (Ramesh et al 1991). Since we have already

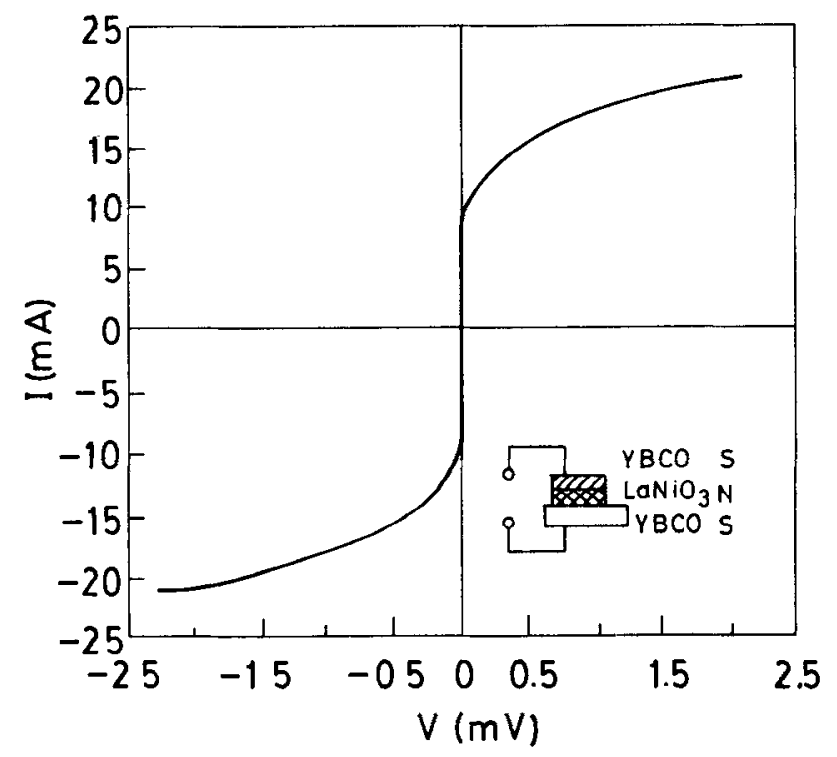

Figure 6. $I-V$ characteristics of $\mathrm{YBCO} / \mathrm{LNO} / \mathrm{YBCO}$ junction. 


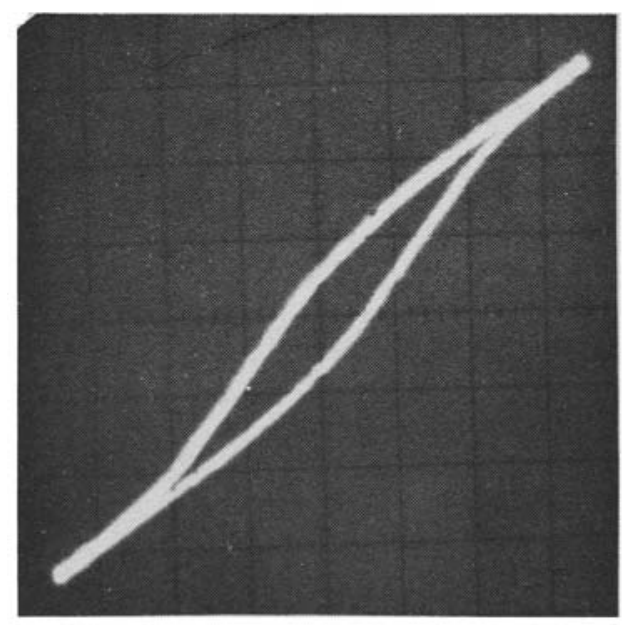

Figure 7. Hysteresis loop of ferroelectric $\mathrm{Bi}_{2} \mathrm{VO}_{5.5}$ film in the $\mathrm{LaNiO}_{3} / \mathrm{Bi}_{2} \mathrm{VO}_{5.5} / \mathrm{LaNiO}_{3} /$ $\mathrm{SiO}_{2} / \mathrm{Si}$ trilayer configuration.

developed processes for $\mathrm{LaNiO}_{3}$ films, we considered it worthwhile to explore this material as an electrode for $\mathrm{Bi}_{2} \mathrm{VO}_{5 \cdot 5}$ ferroelectric oxide (Prasad et al 1993).

$\mathrm{Bi}_{2} \mathrm{VO}_{5.5}$ thin films were grown on $\mathrm{LaNiO}_{3} / \mathrm{SrTiO}_{3}(100)$ as well as $\mathrm{LaNiO}_{3} / \mathrm{SiO}_{2} /$ $\mathrm{Si}$. $\mathrm{LaNiO}_{3}$ metallic film here acted as the bottom electrode. Experiments were carried out with both $\mathrm{Au}$ as well as $\mathrm{LaNiO}_{3}$ as the top electrode. The trilayer $\mathrm{LaNiO}_{3}$ / $\mathrm{Bi}_{2} \mathrm{VO}_{5.5} / \mathrm{LaNiO}_{3}$ film with the $\mathrm{LaNiO}_{3}$ electrodes indeed showed the ferroelectric hysteresis loop shown in figure 7. Such a loop could be obtained with just $5 \mathrm{~V}$ across the ferroelectric oxide layer. The remanent polarization $\left(P_{\mathrm{r}}\right)$ is of the order of $10^{-7} \mathrm{C} / \mathrm{cm}^{2}$. This clearly demonstrates the utility of $\mathrm{LaNiO}_{3}$ as an electrode material. Characteristic ferroelectric property in the form of the hysteresis loop seen here further suggests the growth of stoichiometric $\mathrm{Bi}_{2} \mathrm{VO}_{5.5}$ thin film. It has also been shown that the trilayer growth is indeed epitaxial (Hegde, unpublished).

\subsection{Giant magnetoresistance in $\mathrm{La}_{0.6} \mathrm{~Pb}_{0.4} \mathrm{MnO}_{3}$ thin films}

Giant magnetoresistance (GMR) effect was first observed in $(\mathrm{Fe} / \mathrm{Cr})_{n}$ multilayer thin films. Here, large negative resistance is observed when magnetic field is applied and such an effect is likely to be useful for magnetoresistive 'read' heads in information storage devices. Lanthanum manganates doped with $\mathrm{Ca}, \mathrm{Sr}, \mathrm{Ba}$ and $\mathrm{Pb}$ are known to show ferromagnetic ordering at temperatures below $320 \mathrm{~K}$ and $\mathrm{La}_{0.67} \mathrm{Ba}_{0.33} \mathrm{MnO}_{3}$ thin films did show over 50\% GMR (Von Helmort et al 1993). We considered it worthwhile to pursue this aspect and here we report GMR in $\mathrm{La}_{0 \cdot 6} \mathrm{~Pb}_{0.4} \mathrm{MnO}_{3}$ thin films.

The films of $\mathrm{La}_{0 \cdot 6} \mathrm{~Pb}_{0 \cdot 4} \mathrm{MnO}_{3}$ were prepared by PLD with almost similar conditions as the $\mathrm{LaNiO}_{3}$ films. In figure 8 , we show the $\Delta R / R_{0}$ vs $H$ of $\mathrm{La}_{0.6} \mathrm{~Pb}_{0.4} \mathrm{MnO}_{3}$ thin films. Thus for the first time we show here that over $40 \% \mathrm{GMR}$ is seen in $\mathrm{La}_{0.6} \mathrm{~Pb}_{0.4} \mathrm{MnO}_{3}$ thin films at room temperature. Details of this experiment are published elsewhere (Sundar Manoharan et al 1994). 


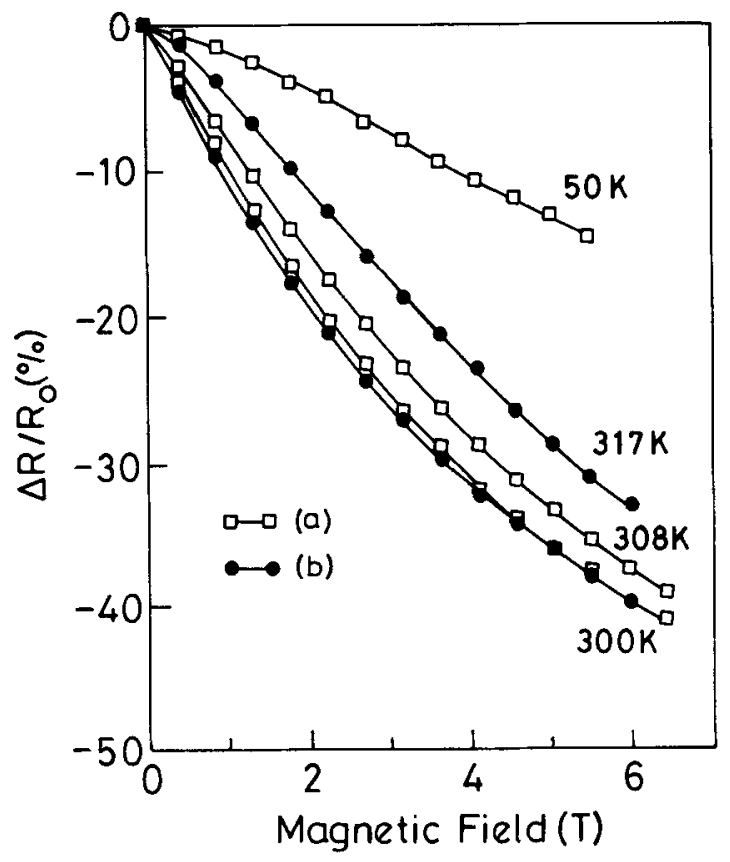

Figure 8. Giant magnetoresistance $\Delta R / R_{0}$ vs magnetic field for ferromagnetic films of (a) as-deposited epitaxial $\mathrm{La}_{0.6} \mathrm{~Pb}_{0.4} \mathrm{MnO}_{3}$ and (b) partially oxygen-desorbed $\mathrm{La}_{0.6} \mathrm{~Pb}_{0.4}$ $\mathrm{MnO}_{3}$.

\section{Conclusions}

We have presented in this article fabrication of epitaxial thin films of Ag-doped YBCO on sapphire, $\mathrm{LaNiO}_{3}$ metallic oxide, ferroelectric oxide and ferromagnetic $\mathrm{La}_{0.6} \mathrm{~Pb}_{0.4}$ $\mathrm{MnO}_{3}$ oxide by pulsed laser deposition and some of their properties. The results presented here indicate that PLD is a versatile technique to fabricate a variety of oxide thin films for various applications. We expect to bring out some practical devices such as microwave transmitters, SQUIDS, ferroelectric switches and ferromagnetic switches out of these oxide thin films.

\section{Acknowledgements}

The author thanks all his associates Ms K M Satyalakshmi; Drs Boben Thomas, Sundar Manoharan, Dhananjay Kumar, N Y Vasanthacharya, K B R Varma; Professors S V Subramanyam, S V Bhat and R M Mallya for their active involvement. and support to make this programme successful. Liberal financial assistance from the Department of Science and Technology, Government of India, to set up a pulsed laser deposition system is gratefully acknowledged.

\section{References}

Bednorz J G and Muller K A 1986 Z. Phys. B64 187

Chaudhari P, Koch R H, Laibowitz R B, McGuine T R and Gambino R J 1987 Phys. Rev. Lett. 582684 
Char K, Antognazza L and Geballe T H 1993 Appl. Phys. Lett. 632420

Dijkkamp D, Venkatesan T, Wu X D, Shaheen S A, Jiswari N, Min-Lee Y H, McLean W L and Croft M 1987 Appl. Phys. Lett. 51619

Hegde M S, Boben Thomas, Vasanthacharya N Y, Bhat S V, Srinivasu V V and Kumar N 1993 Phys. Rev. B48 6465

Hegde M S, Satyalakshmi K M, Mallya R M, Rajeshwari M and Zhang H 1994 J. Mater. Res. 9898

Inam A, Hegde M S, Wu X D, Chase E W, Chang C C, Tarscon J M and Watchman J B 1988 Appl. Phys. Lett. $\mathbf{5 3} 908$

Prasad K V R, Varma K B R, Raju A R, Satyalakshmi K M, Mallya R M and Hegde M S 1993 Appl. Phys. Lett. 631898

Ramesh R, Inam A, Bonnu W A, Wilkem R J, Wu X D, Hegde M S and Venkatesan T 1989 Appl. Phys. Lett. 551138

Ramesh R, Inam A, Chan W K, Wilkens B, Mayers K, Ramchnig K, Hart K L and Tarascon J M 1991 Science 252944

Rogers C T, Hegde M S, Dutta B, Wu X D and Venkatesan T 1989 Appl. Phys. Lett. 552032

Satyalakshmi K M, Mallya R M, Ramanathan K V, Wu X D, Brainard B, Gautier D C, Vasanthacharya N Y and Hegde M S 1993 Appl. Phys. Lett. 621233

Searle C W and Wang S T 1970 Can. J. Phys. 482023

Srinivasu V V, Thomas B. Hedge M S and Bhat S V 1991 Solid State Commun. 79713

Sundar Manoharan S, Vasanthacharya N Y, Hegde M S, Satyalakshmi K M, Prasad V and Subramanian S V 1994 J. Appl. Phys. 763823

Von Helmort R, Wecker J, Holzapfel B, Schultz L and Samwer K 1993 Phys. Rev. Lett. 712331

Wu M K, Ashburgn J R, Torng C J, Hor P H, Meng R L, Gao L C, Huang Z J, Wang Y Q and Chu C W 1987 Phys. Rev. Lett. 58908

Wu X D, Inam A, Hegde M S, Wilkens B, Chang C C, Hwang D M, Nazer L, Venkatesan T, Miura S, Matsubara S and Miyasaki Y 1989 Appl. Phys. Lett. 54754 